\title{
Peri-operative diaphragm ultrasound as a new method of recognizing post-operative residual curarization
}

Jiaxin Lang ${ }^{1}$, Yuchao Liu', Yuelun Zhang ${ }^{2}$, Yuguang Huang ${ }^{1}$ and Jie Yi ${ }^{1 *}$

\begin{abstract}
Background: This study sought to evaluate the diagnostic accuracy of peri-operative diaphragm ultrasound in assessing post-operative residual curarization (PORC).
\end{abstract}

Methods: Patients undergoing non-thoracic and non-abdominal surgery under general anaesthesia were enrolled from July 2019 to October 2019 at Peking Union Medical College Hospital. A train-of-four ratio (TOFr) lower than 0.9 was considered as the gold standard for PORC. Diaphragm ultrasound parameters included diaphragmatic excursion (DE) and diaphragm thickening fraction (DTF) during quiet breathing (QB) and deep breathing (DB). The diaphragm excursion fraction (DEF) was calculated as the DE-QB divided by the DE-DB. The diaphragm excursion difference (DED) was defined as DE-DB minus DE-QB. Receiver operating characteristic curve analysis was used to determine the cutoff values of ultrasound parameters for the prediction of PORC.

Results: In total, 75 patients were included, with a PORC incidence of $54.6 \%$. The DE-DB and DED were positively correlated with the TOFr, while the DEF was negatively correlated with the TOFr. The DE-DB cut-off value for predicting PORC was $3.88 \mathrm{~cm}$, with a sensitivity of $85.4 \%$ (95\% confidence interval [Cl]: $70.1-93.9 \%$ ), specificity of $64.7 \%$ (95\% Cl: 46.4-79.7\%), positive likelihood ratio of 2.42 ( $95 \%$ Cl 1.5-3.9), and negative likelihood ratio of 0.23 (95\% Cl: $0.1-0.5)$. The DED cut-off value was $1.5 \mathrm{~cm}$, with a specificity of $94.2 \%$ (95\% Cl: $80.3-99.3 \%)$, sensitivity of $63.4 \%$ (95\% Cl: $46.9-$ 77.9\%), positive likelihood ratio of 10.78 (95\% Cl: 2.8-42.2), and negative likelihood ratio of 0.39 (95\% Cl: 0.3-0.6).

Conclusions: Peri-operative diaphragm ultrasound may be an additional method aiding the recognition of PORC, with DED having high specificity.

Keywords: Diaphragm ultrasound, Diagnostic test, Neuromuscular monitor, Train-of-four, Post-operative residual Curarization

\section{Background}

Post-operative residual curarization (PORC) remains an essential clinical challenge, with an incidence ranging from 7 to $88 \%$ [1]. Residual blockade leads to an

\footnotetext{
*Correspondence: easyue@163.com

${ }^{1}$ Department of Anesthesiology, Chinese Academy of Medical Science, Peking Union Medical College Hospital, No 1, Shuaifuyan, Dongcheng district, Beijing 100730, China

Full list of author information is available at the end of the article
}

increased risk of respiratory complications, including airway obstruction, hypoxia, and reintubation, as well as to prolonged lengths of stay in the post-anaesthesia care unit (PACU) [2-4]. Neuromuscular monitoring of the train-of-four ratio (TOFr) at the adductor pollicis is considered a gold standard in reflecting sufficient recovery from the neuromuscular blockade, whereby a patient is considered to have sufficiently recovered if the TOFr is above 0.9 [5]. However, due to complicated procedures, the requirement of specific equipment, ease of interference, and inconvenience of the test, the use of a otherwise in a credit line to the material. If material is not included in the article's Creative Commons licence and your intended use is not permitted by statutory regulation or exceeds the permitted use, you will need to obtain permission directly from the copyright holder. To view a copy of this licence, visit http://creativecommons.org/licenses/by/4.0/. The Creative Commons Public Domain Dedication waiver (http://creativecommons.org/publicdomain/zero/1.0/) applies to the data made available in this article, unless otherwise stated in a credit line to the data. 
neuromuscular monitor remains clinically restricted [6], especially in China [7]. Many Chinese hospitals cannot afford to equip neuromuscular monitors in every operating room due to limited medical funding. The incidence of PORC remains quite high. Thus, it is important to investigate new ways to detect PORC when neuromuscular monitoring equipment is inaccessible.

The diaphragm is a major respiratory muscle, accounting for $60-70 \%$ of the respiratory workload. Its dysfunction involves post-operative respiratory failure, especially in the context of prolonged mechanical ventilation $[8$, 9]. Ultrasound is a non-invasive and visible method of assessing diaphragm morphology in both healthy volunteers [10] and intensive care unit (ICU) patients [11], representing a reproducible, feasible, and valid $[12,13]$ technique, according to previous research. Diaphragm ultrasound (DUS) parameters, including diaphragmatic excursion (DE) and diaphragm thickening fraction (DTF), correlate to inspiratory nasal pressure and transdiaphragmatic pressure in spontaneous respiration [1417]. As such, DUS can be used as a substitute to predict diaphragm muscle strength, since direct measurement would be otherwise invasive and likely to incur severe complications.

The use of DUS in the evaluation of diaphragm involvement in neuromuscular disease and in the prediction of weaning mechanical ventilation in the ICU has been reported recently [18]. The peri-operative examination of diaphragm function is of great value, but is seldom performed in the operating room.

The purpose of this study was to assess the diagnostic accuracy of ultrasound parameters in recognizing residual neuromuscular blockade, using TOFr as the reference standard, in patients receiving general anaesthesia with nondepolarizing neuromuscular blockade for non-thoracic and non-abdominal surgery.

\section{Materials and methods Participants}

This was a prospective observational research study approved by the Institutional Review Board (IRB) of the Peking Union Medical College Hospital (PUMCH) on May 21, 2019 (ZS-1984). Written informed consent was obtained from all subjects before pre-operative evaluation by an anaesthesiologist. This manuscript adheres to the applicable STARD [19] guidelines.

Patients scheduled for elective non-abdominal and non-thoracic surgery in the PUMCH who were administered anaesthesia by a specific anaesthesiologist were consecutively enrolled every Thursday in a selected operation room. All patients aged 18-65 years with an
American Society of Anesthesiologists (ASA) physical status classification of I or II were recruited.

\section{Anaesthesia protocol}

Anaesthesia was induced with fentanyl $2 \mu \mathrm{g} / \mathrm{kg}$, midazolam $1 \mathrm{mg}$, and propofol $1-2 \mathrm{mg} / \mathrm{kg}$, after blood pressure, electrocardiography, and pulse oxygen saturation $\left(\mathrm{SpO}_{2}\right)$ were monitored and an intravenous cannula was established. Neuromuscular monitoring was calibrated and stabilized before rocuronium $(0.6 \mathrm{mg} / \mathrm{kg})$ administration. After intubation, inhaled anaesthetic sevoflurane combined with $50 \%$ nitrous oxide in oxygen was used to maintain a minimal alveolar concentration within the range of 0.9-1.2 during the operation. Fentanyl, remifentanil, and rocuronium were administered as necessary. The administration of neuromuscular blocking drugs was ceased approximately $30 \mathrm{~min}$ prior to the end of surgery. When the anaesthesiologist determined that the patient had adequately regained consciousness, myodynamia, respiratory function, and airway protection, the patient was extubated.

The TOFr within 1 minute before extubation was recorded. Post-operative DUS was performed immediately after extubation, such that the time interval between the TOFr before extubation and post-operative DUS parameters was less than $2 \mathrm{~min}$. The modified observer's assessment of alert/sedation (OAA/S) score immediately after extubation was recorded. The anaesthesiologist was blinded to the TOFr results to prevent researcher bias. After tracheal extubation, the patients immediately underwent DUS, and were transferred to the PACU. The modified Aldrete score was evaluated in the PACU, 15 min after extubation [20].

Patient demographic data, neuromuscular blocking agent dose, total opioid consumption, duration of surgery, and reintubation events were recorded. The patients were followed up for 1 month for post-operative pulmonary complications, including upper airway obstruction, bronchospasm, pneumonia, and exacerbation of chronic lung disease, though clinical documents records and telephone follow-up.

\section{DUS protocol}

Diaphragm ultrasonograms were acquired on the right side pre-operatively and post-operatively with a Navi series ultrasonogram (Wisonic, Shenzhen, China) by an independent experienced anaesthesiologist who was blind to the TOFr results to avoid researcher bias. To ensure the reproducibility of the ultrasound examination, the location of the transducer was carefully marked, and the post-operative DUS examination was acquired at the same location within 2 minutes of extubation. The 
thickness of the diaphragm was assessed at the appositional zone of the diaphragm from images obtained at the 8-9th intercostal space on the anterior axillary line using a B-mode ultrasound with a $4-15 \mathrm{MHz}$ sector array transducer at the end of inspiration and expiration. The DTF was calculated according to the following equation, during deep breathing (DB), pre-operatively (pre-DTFDB) and post-operatively (DTF-DB).

DTF $=\frac{\text { Thickness at the end of inspiration-Thickness at the end of expiration }}{\text { Thickness at the end of expiration }}$

The DE between inspiration and expiration was examined by $\mathrm{M}$-mode ultrasonography with a $1-4 \mathrm{MHz}$ curved array transducer from a subcostal area between the midclavicular and anterior axillary lines. The probe was directed cranially and dorsally, so that the ultrasound beam reached perpendicularly to the right diaphragmatic dome. Excursions during quiet breathing (DE-QB) and deep breathing (DE-DB) were assessed pre-operatively (pre-DE-QB and pre-DE-DB, respectively) and post-operatively (DE-QB and DE-DB, respectively). Two new parameters were defined, the diaphragm excursion fraction (DEF) and the diaphragm excursion difference (DED). These parameters were measured twice and averaged. The DEF was calculated as the DE-QB divided by the DE-DB, pre-operatively (pre-DEF) and post-operatively (DEF). The DED was defined as the DE-DB minus the $\mathrm{DE}-\mathrm{QB}$, and was also calculated pre-operatively (preDED) and post-operatively (DED).

\section{TOF monitoring}

Acceleromyography (neuromuscular acceleromyography module; BeneVision N12, Mindray, China) was used to assess the acceleration of the adductor pollicis muscle after electric stimulation. After the skin was cleaned thoroughly, two surface electrodes were positioned over the ulnar nerve at the wrist of the dominant hand. The distance between the two electrodes was between 3 and $6 \mathrm{~cm}$. An acceleration transducer was attached distally to the interphalangeal joint of the thumb. No preload was applied. The hand with the monitor was positioned on the bracket and securely fixed to prevent any movement of the fingers other than the thumb during each assessment. The skin temperature over the adductor pollicis muscle was maintained at $>32^{\circ} \mathrm{C}$. Following anaesthesia induction, the maximal response was obtained using single-twitch stimulation ( $2 \mathrm{~Hz}$ for $0.2-\mathrm{ms}$ square wave) by gradually increasing the electrical current from $10 \mathrm{~mA}$. A supramaximal response was triggered by an electrical current $20 \%$ above that which was necessary for a maximal response to reduce post-recovery drift. TOF patterns (a set of four supramaximal stimuli at $2 \mathrm{~Hz}$ for $0.2 \mathrm{~ms}$ ) at 12-s intervals were applied to test the stability of baseline responses (variation of the TOFr $<5 \%$ ) for $3 \mathrm{~min}$. If baseline responses were unstable, the device was recalibrated [21]. The TOFr (T4:T1) was used to evaluate neuromuscular recovery. The TOFr within 1 minute before extubation was recorded. To prevent any bias, anaesthesiologists and ultrasound operators were blind to the TOFr results. PORC was defined as a TOFr at extubation of under 0.9 .

\section{Statistical analysis}

Sample size calculation was based on a preliminary experiment with a predictive sensitivity of 0.733 and predictive specificity of 0.667 . With an alpha error of 0.05 , beta error of 0.1 , and no consideration of loss to followup, 75 patients were needed in current diagnostic test.

Patients with a TOFr value at extubation of over 0.9 comprised the non-PORC group, and the remaining patients comprised the PORC group (i.e. $\mathrm{TOFr}<0.9$ ). The discrimination performance of ultrasound parameters in identifying PORC was assessed using receiver operator characteristic (ROC) curve analyses, and the corresponding ROC curves were drawn using GraphPad Prism (GraphPad Software, Inc., State of California, USA). As DUS is rarely used peri-operatively to evaluate muscle function recovery, there are no well-accepted cut-off values of ultrasound parameters (DTF, DE, DEF, and DED) for the prediction of residual curarization. A higher area under the ROC curve (AUC) was considered as reflective of better test performance. The cut-off value was thereby identified by the point with the highest Youden index on the ROC curve to predict residual curarization, or equivalently, the highest sensitivity plus specificity. The sensitivity, specificity, positive likelihood ratio $(\mathrm{LR}+)$, negative likelihood ratio (LR-), positive predictive value (PPV), and negative predictive value (NPV), with corresponding 95\% confidence intervals, were calculated at the cut-off value for each ultrasound parameter (DTF-DB, DE-DB, DEF, and DED). The Spearman correlation was used to evaluate the associations between the TOFr value at extubation and post-operative diaphragm parameters.

For all analyses, a two-sided $P$-value $<0.05$ was considered significant. IBM SPSS Statistics 23.0 (Armonk, NY, USA) software was used for data analysis.

\section{Results}

Participants' baseline demographic and clinical characteristics

A total of 86 patients (age, $39 \pm 11$ years) undergoing elective non-thoracoabdominal operations were invited to be assessed for initial eligibility between 1 August and 30 October, 2019. A total of 75 patients were finally enrolled in this study. Figure 1 shows the flowchart representing the patient enrolment process, the reason for excluding certain patients, and the procedure of the study. Fifty-two 


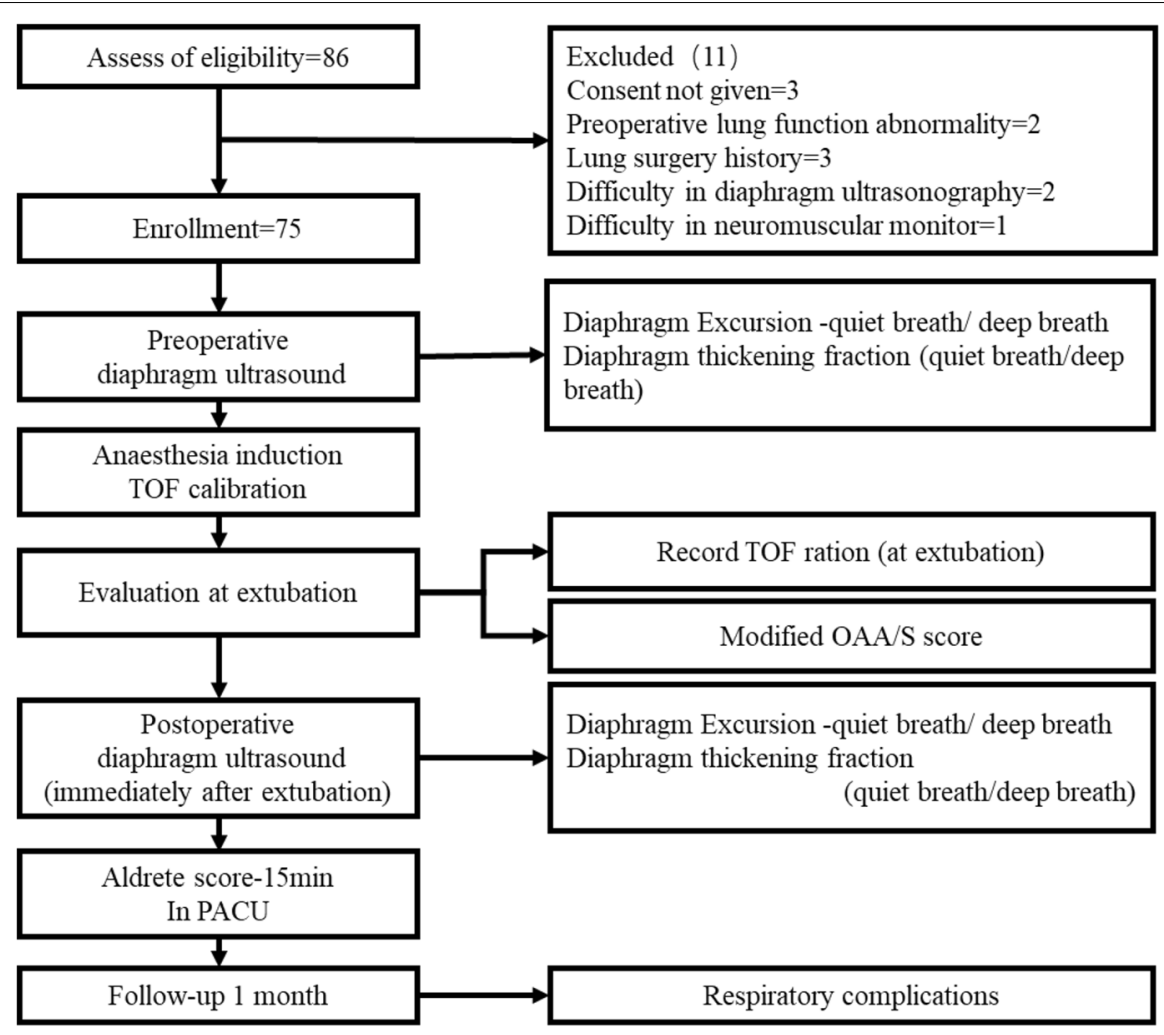

Fig. 1 Recruitment and follow-up flow chart. Seventy-five patients receiving non-thoracic and non-abdominal elective surgery at the Peking Union Medical College Hospital from August to October 2019 were recruited; each provided signed informed consent before the diaphragm ultrasonogram. Baseline diaphragm ultrasound including diaphragm excursion and diaphragm thickening fraction of quiet breathing and deep breathing were acquired prior to operation. Abbreviation: PACU, post-anaesthesia care unit; TOF, Train of Four

patients were assessed as ASA level I, and 23 patients as ASA level II. Residual curarization at extubation was identified in 41 patients (54.7\%), according to the criterion of a TOFr at extubation of $<0.9$. Patients were divided into PORC and non-PORC groups according to whether the TOFr was lower than 0.9 at extubation. Clinical data and DUS parameters are shown in Table 1. There were no significant differences in demographic characteristics, pre-operative diaphragm variables, fentanyl dose, or modified O/AAS scores between the two groups (Table 1).

\section{Accuracy of DUS for the prediction of PORC}

DE-DB $(R=0.539, \quad P<0.001), \quad$ and DED $(R=0.669$, $P<0.001)$ were positively correlated with TOFr at extubation in moderate degree, while a weak correlation was found between DTF-DB and TOFr at extubation $(R=0.351, \quad P=0.045)$. DEF $\quad(R=-0.638$, $P<0.001)$ was inversely correlated with TOFr at extubation (Fig. 2). Figure 3 shows the ROC curves of four DUS parameters for the prediction of PORC. Table 2 provides the cut-off values, sensitivity, specificity, LR+/-, PPV, and NPV of these DUS parameters. Among all these parameters, the DE-DB cut-off value for the prediction of the PROC was $3.88 \mathrm{~cm}$, with a highest sensitivity of $85.4 \%$ (70.1-93.9\%), specificity of $64.7 \%$ (46.4-79.7\%), while, the DED cut-off value was $1.5 \mathrm{~cm}$, with a highest specificity of $94.2 \%$ (80.3-99.3\%), sensitivity of $63.4 \%$ (46.9-77.9\%), $\mathrm{LR}+$ of 10.78 (2.8-42.2), and PPV of 92.9 (76.9-98.1).

\section{Clinical outcomes in the PORC and non-PORC groups}

The modified Aldrete score was lower in the PORC group than in the non-PORC group $(8.2 \pm 1.2,9.6 \pm 0.7$, $P<0.001)$, mainly because of a lower $\mathrm{SpO}_{2}$. There were no cases of airway obstruction, bronchospasm, pulmonary aspiration of gastric contents, apnoea, reintubation, unexpected ICU admission, atelectasis, or pneumonia in either group.

\section{Discussion}

This is the first diagnostic test focusing on the use of DUS parameters to recognize PORC. Our findings suggest that DE-DB and DTF-DB are significantly correlated with 
Table 1 Clinical characteristics and baseline ultrasound indicators between patients with and without residual neuromuscular blockade

\begin{tabular}{|c|c|c|c|}
\hline & $\begin{array}{l}\text { non-PORC group } \\
(N=34)\end{array}$ & $\begin{array}{l}\text { PORC group } \\
(N=41)\end{array}$ & $P$-value \\
\hline Female (\%) & 58.8 & 73.1 & 0.131 \\
\hline $\mathrm{Age}^{\mathrm{a}}$ & $36.4 \pm 11.5$ & $41.4 \pm 10.2$ & 0.065 \\
\hline ASA I (\%) & 73.5 & 65.9 & 0.616 \\
\hline Body mass index $(\mathrm{kg} / \mathrm{m} \wedge 2)$ & $22.95 \pm 3.82$ & $23.58 \pm 3.01$ & 0.429 \\
\hline Fentanyl dose ${ }^{a}(\mu \mathrm{g})$ & $224.3 \pm 93.8$ & $212.8 \pm 32.2$ & 0.932 \\
\hline Rocuronium/weight ${ }^{\mathrm{a}}(\mathrm{mg} / \mathrm{kg})$ & $0.71 \pm 0.15$ & $0.74 \pm 0.13$ & 0.239 \\
\hline Anaesthesia time ${ }^{\mathrm{a}}$ (minute) & $87.6 \pm 30.9$ & $73.2 \pm 18.9$ & 0.042 \\
\hline Pre-Thickening fraction ${ }^{a}$ & $0.50 \pm 0.27$ & $0.53 \pm 0.23$ & 0.252 \\
\hline Pre-Diaphragm excursion (QB) & $1.53 \pm 0.47$ & $1.45 \pm 0.43$ & 0.466 \\
\hline Pre-Diaphragm excursion (DB) & $4.88 \pm 1.21$ & $4.70 \pm 1.14$ & 0.518 \\
\hline Pre-Diaphragm excursion fraction & $0.32 \pm 0.10$ & $0.32 \pm 0.09$ & 0.821 \\
\hline Pre-Diaphragm excursion difference & $3.35 \pm 1.11$ & $3.25 \pm 1.04$ & 0.684 \\
\hline O/AAS-extubation ${ }^{\mathrm{a}}$ & $1.2 \pm 0.4$ & $1.5 \pm 0.5$ & 0.155 \\
\hline TOFr at extubation & $95.8 \pm 7.5$ & $53.4 \pm 21.9$ & $<0.001$ \\
\hline Thickening fraction ${ }^{a}$ & $0.44 \pm 0.22$ & $0.34 \pm 0.18$ & 0.039 \\
\hline Diaphragm excursion (QB) & $1.48 \pm 0.56$ & $1.46 \pm 0.52$ & 0.868 \\
\hline Diaphragm excursion (DB) & $4.11 \pm 0.97$ & $2.89 \pm 1.37$ & $<0.001$ \\
\hline Diaphragm excursion fraction & $0.36 \pm 0.12$ & $0.56 \pm 0.19$ & $<0.001$ \\
\hline Diaphragm excursion difference & $2.63 \pm 0.82$ & $1.43 \pm 1.10$ & $<0.001$ \\
\hline
\end{tabular}

${ }^{a}$ Abnormal distribution, Mann-Whitney rank sum test was used in group comparation

Abbreviations: ASA American Society of Anesthesiologists classification of physical status, $Q B$ quiet breathing, $D B$ deep breathing

the TOFr. Patients with residual curarization had a much lower DTF DB, DE-DB, DEF, and DED. In particular, the DED had a low sensitivity and high specificity in recognizing PORC.

\section{PORC and baseline DUS parameters}

The PORC incidence in the current study was $54.6 \%$, which is within the common range of published studies in China, but is higher than that in some recent American and European studies. Neuromuscular monitoring was performed by an independent investigator according to neuromuscular measurement guidelines. Both the anaesthesiologists and ultrasound operators were blind to the TOFr results to prevent researcher bias. DUS was performed immediately after extubation to shorten the time interval between the DUS and TOFr measurements. The DTF [12, 22] and DE [23] have been validated as repeatable and reproducible in recent studies. In addition, it is easier to detect the DE on right hemidiaphragm than on the left hemidiaphragm, and the result is more reproducible, according to previous research [24]. Thus, only right hemidiaphragm parameters were measured in this study.
Multiple factors (e.g. sex, age, BMI, and lung function) may influence DUS parameters [25]. However, no significant differences were found in sex, age, or BMI between the two groups in our study, which minimized selection bias. The baseline DE in our study was lower than that reported in French and Canadian studies [14, 24]. DE measurement was performed directly at the diaphragm dome to reduce the methodological weaknesses of our study. The difference in baseline DE may be due to the different ethnics and BMI of patient samples between our study(Asian, smaller BMI) and previous research (Most of Caucasian, higher BMI). Additionally, we found no significant differences between females and males, although many studies have shown sex differences in DE.

\section{Correlation between TOFr and diaphragm parameters}

DUS is commonly used to assess diaphragmatic function recovery in the ICU [26, 27], but is rarely used in peri-operative situations. Only one clinical trial was designed to use both DUS and TOFr to evaluate the function of neostigmine and sugammadex as reversal drugs [26]. This study is the first to report correlations between DUS parameters and the TOFr. The TOFr was 

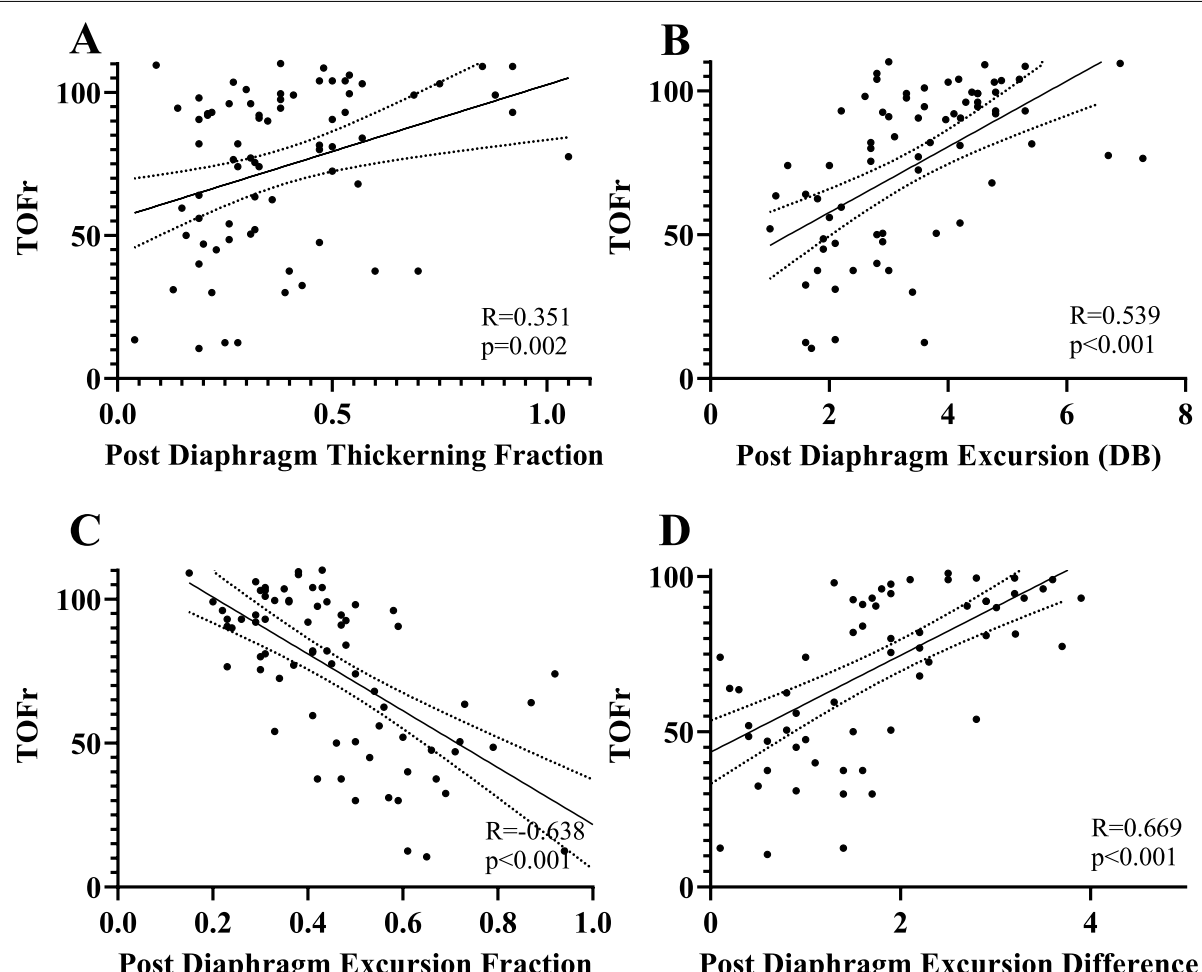

Fig. 2 TOF ratio at extubation correlate with post-operative diaphragm ultrasound indicators. A Diaphragm thickening fraction (DTF), B Diaphragm excursion (DB), C Diaphragm excursion fraction (DEF), D Diaphragm excursion difference (DED). Abbreviation: DB, deep breathing; $Q B$, quiet breathing; TOF, Train of Four

significantly and positively associated with DE-DB and DTF-DB in the bivariate correlation analysis (Fig. 2). This result does not contradict the traditional notion that the diaphragm is resistant to neuromuscular blockade, and diaphragm function clearly recovered earlier than did other muscular functions $[28,29]$. We found no difference in DE-QB between the two groups, which suggests that early diaphragm recovery occurred in order to maintain the ability to breathe quietly. Additionally, we found that patients with PORC had a lower DE-DB and DTF-DB compared to patients who experienced full neuromuscular function recovery, indicating that diaphragm function was not fully recovered in the PORC group, and the ability to breathe deeply was compromised. Thus, the DE-DB and DTF can reflect compromised diaphragm recovery, as well as the curarization status. To rule out the influence of sedation [30], modified O/AAS scores were assessed, and no significant differences were found between the two groups. As a result, we defined the DEF and DED to represent the differences in diaphragm movements between QB and DB. Both DEF and DED were closely correlated with the TOFr.
The observed correlations provide insight into the diagnostic process of PORC. We compared the ROC curves of the DE-DB, DTF-DB, DEF, and DED. DED had the largest AUC (0.836, 95\% CI: 0.732-0.911, $P<0.001)$, reported for the first time in the current study. The DED cut-off value was $1.5 \mathrm{~cm}$, and had an relatively high specificity (94.1\%) and low sensitivity (63.4\%), as well as a high LR+ (10.78, 95\% CI: 2.8-42.2) and high PPV (92.9, 95\% CI: 76.9-98.1), when the PORC incidence was $54.6 \%$, which means if a lower DED was detected,the possibility of PORC was $92.9 \%$, but a normal DED cannot exclude PORC because of high false negative rate. These results can be attributed to the physiological characteristics of the diaphragm, since the diaphragm functionally recovers early after the administration of the neuromuscular blockade. DE-DB had a higher sensitivity (85.4\%), thus the combination DE-DB and DED might provide better prediction of PORC, but need further study.

Although ultrasound parameters only achieved a best AUC of 0.836 and LR+ of 10.78 (for the DED), indicating barely acceptable accuracy, we still believe that the use of these parameters are highly clinical relevant. Ultrasound methods may serve as an important method for rapidly 


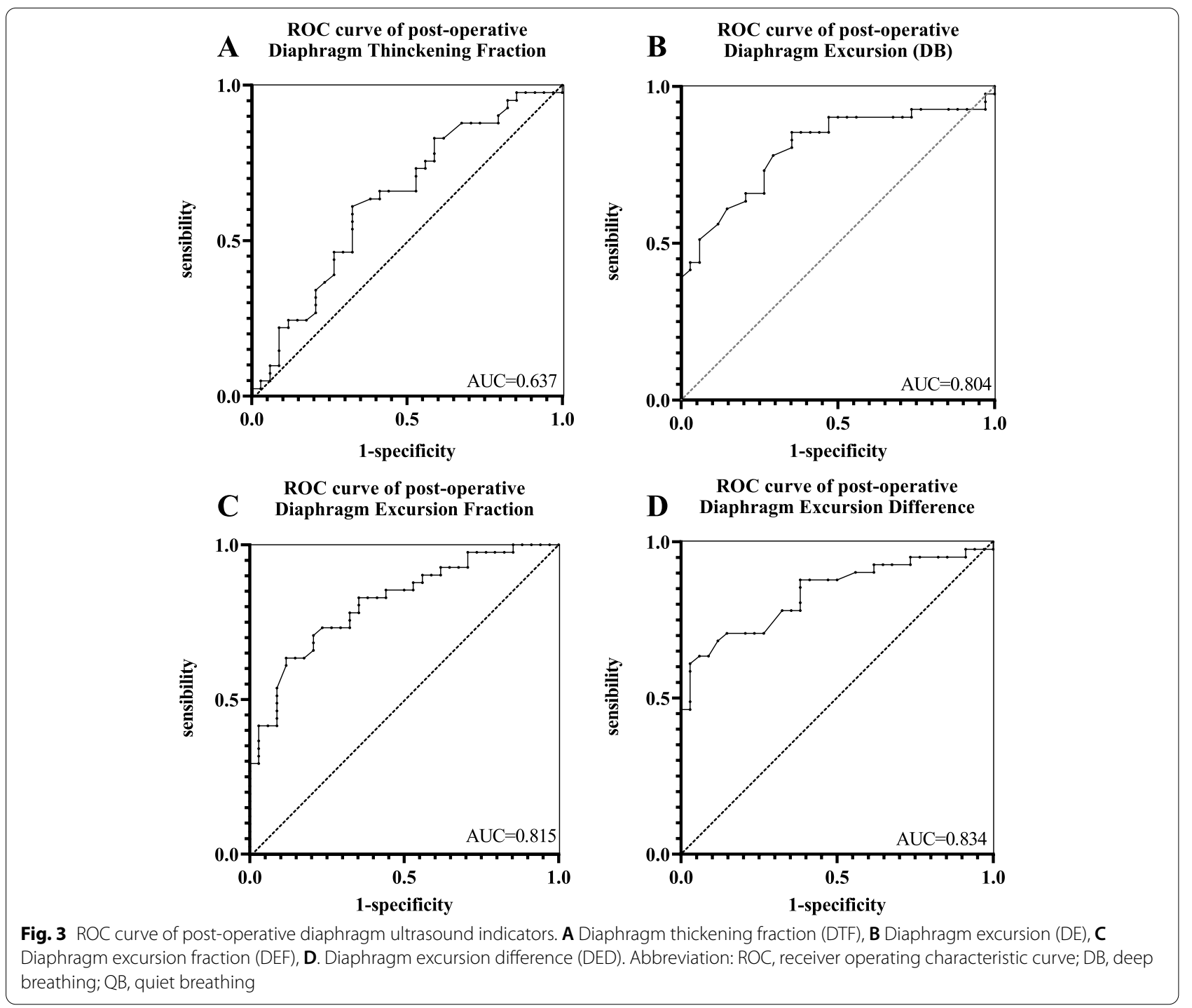

Table 2 Diagnostic accuracy of different diaphragm indicators after extubation including diaphragm thickening fraction (DB), diaphragm excursion (DB), diaphragm excursion fraction, and diaphragm excursion difference

\begin{tabular}{|c|c|c|c|c|c|c|c|c|c|}
\hline & AUC $(95 \% \mathrm{Cl})$ & $\begin{array}{l}\text { Youden } \\
\text { Index }\end{array}$ & Cut-off Value & $\begin{array}{l}\text { Sensitivity } \\
(\%) \\
(95 \% \mathrm{Cl})\end{array}$ & $\begin{array}{l}\text { Specificity } \\
(\%) \\
(95 \% \mathrm{Cl})\end{array}$ & $\begin{array}{l}\mathrm{LR}+ \\
(95 \% \mathrm{Cl})\end{array}$ & $\begin{array}{l}\text { LR- } \\
(95 \% \mathrm{Cl})\end{array}$ & $\begin{array}{l}\text { PPV } \\
(95 \% \mathrm{Cl})\end{array}$ & $\begin{array}{l}\text { NPV } \\
(95 \% \mathrm{Cl})\end{array}$ \\
\hline DTF (DB) & $\begin{array}{l}0.637(0.517- \\
0.745)\end{array}$ & 0.286 & 0.33 & $\begin{array}{l}61.0 \\
(44.5-75.8)\end{array}$ & $\begin{array}{l}67.7 \\
(49.5-82.6)\end{array}$ & $1.88(1.1-3.2)$ & $0.58(0.4-0.9)$ & $\begin{array}{l}69.4 \\
(56.9-79.7)\end{array}$ & $\begin{array}{l}59.0 \\
(47.9-69.2)\end{array}$ \\
\hline $\mathrm{DE}(\mathrm{DB})$ & $\begin{array}{l}0.804(0.703- \\
0.905)\end{array}$ & 0.501 & 3.88 & $\begin{array}{l}85.4 \\
(70.1-93.9)\end{array}$ & $\begin{array}{l}64.7 \\
(46.4-79.7)\end{array}$ & $2.42(1.5-3.9)$ & $0.23(0.1-0.5)$ & $\begin{array}{l}74.5 \\
(64.5-82.4)\end{array}$ & $\begin{array}{l}78.6 \\
(62.7-88.9)\end{array}$ \\
\hline DEF & $\begin{array}{l}0.815(0.708- \\
0.895)\end{array}$ & 0.501 & 0.44 & $\begin{array}{l}70.73 \\
(54.5-83.9)\end{array}$ & $\begin{array}{l}79.41 \\
(62.1-91.3)\end{array}$ & $3.44(1.7-6.8)$ & $0.37(0.2-0.6)$ & $\begin{array}{l}80.6 \\
(67.5-89.2)\end{array}$ & $\begin{array}{l}69.2 \\
(57.6-78.9)\end{array}$ \\
\hline DED & $\begin{array}{l}0.836(0.732- \\
0.911)\end{array}$ & 0.575 & 1.5 & $\begin{array}{l}63.4 \\
(46.9-77.9)\end{array}$ & $\begin{array}{l}94.12 \\
(80.3-99.3)\end{array}$ & $\begin{array}{l}10.78 \\
(2.8-42.2)\end{array}$ & $0.39(0.3-0.6)$ & $\begin{array}{l}92.9 \\
(76.9-98.1)\end{array}$ & $\begin{array}{l}68.1 \\
(58.6-76.3)\end{array}$ \\
\hline
\end{tabular}

Abbreviations: $A U C$ area under curve of ROC curve, $C l$ confidential interval, $L R+$ positive likelihood ratio, $L R$ - negative likelihood ratio, $P P V$ positive predictive value, $N P V$ negative predictive value, DTF (DB) Diaphragm thickening fraction (Deep breathing), $D E$ (DB) Diaphragm excursion (Deep breathing), DEF diaphragm excursion fraction, DED Diaphragm excursion difference 
screening and monitoring for PORC, and help prevent complications due to PORC in surgical patients.

\section{Clinical perspective}

Neuromuscular monitoring is still the gold standard for recognizing PORC, but it requires dedicated equipment, as well as precise calibration, and may incur discomfort in patients. Additionally, most Chinese centres only have a small number of neuromuscular monitor devices, insufficient for all patients under general anaesthesia, due to restricted medical funding. A DUS examination can help anaesthesiologists in detecting patients with PORC in the PACU and deciding whether or not to add an antagonist of neuromuscular functioning, without incurring discomfort in patients, when neuromuscular monitoring is not available. Due to the widespread use of ultrasound-guided regional blocks, one ultrasound device is usually available in most anaesthesiology departments in China. Therefore, this study can provide an alternative method for recognizing PORC, taking full advantage of the ultrasound devices available, rather than purchasing new neuromuscular monitor devices. In addition, DUS provides more insight into respiratory muscle function; thus, patients with respiratory disorders may benefit from DUS examination during the peri-operative period for early extubation.

\section{Limitations}

Although a DUS examination has high reproducibility and feasibility, its quality and validity rely on the performance of the practitioners. Training and practice are required to master DUS skills [31]. In our study, DUS parameters were measured by one independent doctor who was blind to the TOFr result; thus, the influence of the operator was minimized, rendering the results more credible and homogeneous. However, this may restrict the generalizability of DUS application in recognizing PORC in the actual clinical conditions. Thoracic cardiac and abdominal surgery may affect diaphragm functions, which may influence post-operative DUS parameters. Additionally, the incision pain in these surgeries may restrict the voluntary movement of breathing [32,33], and the incision site may affect ultrasound measurements; as a result, abdominal and thoracic surgeries were excluded from our research. Deep neuromuscular blockade is mostly required in abdominal and thoracic surgery [34]; as such, assessing how best to use DUS to identify PORC in patients undergoing abdominal and thoracic surgery warrants further research. Moreover, the muscle function recovery of the larynx is slower than that of the diaphragm, and this recovery is essential for maintaining an open upper airway [29]. As such, respiratory function integrity cannot be ensured, even if diaphragm function is fully recovered, due to the slow recovery of the laryngeal muscle. Finally, this study is an exploration with limited sample size, so further studies with larger sample size and variable clinical conditions are needed.

\section{Conclusions}

Peri-operative DUS may be an additional method contributing to the recognition of PORC, with DED having high specificity.

\section{Abbreviations}

AUC: Area under the curve; ASA: American Society of Anesthesiologists; DB: Deep breathing; DED: Diaphragm excursion difference; DEF: Diaphragm excursion fraction; DTF: Diaphragm thickening fraction; DUS: Diaphragm ultrasound; DE: Diaphragmatic excursion; ICU: Intensive care unit; OAA/S: Observer's assessment of alert/sedation; PUMCH: Peking Union Medical College Hospital; PACU : Post-anaesthesia care unit; post-: Post-operative; PORC: Post-operative residual curarization; pre-: Pre-operative; $\mathrm{SpO}_{2}$ : Pulse oxygen saturation; QB: Quiet breathing; ROC: Receiver operator characteristic; TOFr: Train-of-four ratio.

\section{Acknowledgements}

Not applicable.

\section{Authors' contributions}

Jiaxin Lang helped to manage this project, performed ultrasound examinations on all patients, and completed the manuscript draft. Yuchao Liu helped to monitor the TOFr. Yuelun Zhang helped to perform statistical analyses. Yuguang Huang helped in communication with the surgery department. Jie Yi provided this concept and directed the design of this study. All authors read and approved the final version of the manuscript.

\section{Funding}

Not applicable.

\section{Availability of data and materials}

The datasets used and/or analysed during the current study are available from the corresponding author on reasonable request.

\section{Declarations}

\section{Ethics approval and consent to participate}

This was a prospective observational research study approved by the Institutional Review Board (IRB) of the Peking Union Medical College Hospital (PUMCH) on May 21, 2019 (ZS-1984). Written informed consent was obtained from all subjects before pre-operative evaluation by an anaesthesiologist. All methods were carried out in accordance with relevant guidelines and regulations under ethics approval and consent to participate.

\section{Consent for publication \\ Not applicable.}

\section{Competing interests}

The authors certify that there is no conflict of interest with any financial organization regarding the material discussed in the manuscript. 


\section{Author details}

${ }^{1}$ Department of Anesthesiology, Chinese Academy of Medical Science, Peking Union Medical College Hospital, No 1, Shuaifuyan, Dongcheng district, Beijing 100730, China. ${ }^{2}$ Medical Research Center, Chinese Academy of Medical Science, Peking Union Medical College Hospital, Beijing 100730, China.

Received: 22 February 2021 Accepted: 26 October 2021 Published online: 19 November 2021

\section{References}

1. Baillard C. Incidence and complications of post operative residual paralysis. Ann Fr Anesth Reanim. 2009;28(Suppl 2):S41-5. https://doi. org/10.1016/s0750-7658(09)72486-4.

2. Brull SJ, Kopman AF. Current status of neuromuscular reversal and monitoring: challenges and opportunities. Anesthesiology. 2017;126(1):173-90. https://doi.org/10.1097/aln.0000000000001409.

3. Saager L, Maiese EM, Bash LD, Meyer TA, Minkowitz H, Groudine S, et al. Incidence, risk factors, and consequences of residual neuromuscular block in the United States: the prospective, observational, multicenter RECITE-US study. J Clin Anesth. 2019;55:33-41. https://doi.org/10. 1016/j.jclinane.2018.12.042.

4. Grabitz SD, Rajaratnam N, Chhagani K, Thevathasan T, Teja BJ, Deng H, et al. The effects of postoperative residual neuromuscular blockade on hospital costs and intensive care unit admission: a population-based cohort study. Anesth Analg. 2019;128(6):1129-36. https://doi.org/10. 1213/ane.0000000000004028.

5. Naguib M, Brull SJ, Kopman AF, Hunter JM, Fülesdi B, Arkes HR, et al. Consensus Statement on Perioperative Use of Neuromuscular Monitoring. Anesth Analg. 2018:127(1):71-80. https://doi.org/10.1213/ane.0000000000002670.

6. Murphy GS. Neuromuscular monitoring in the perioperative period. Anesth Analg. 2018;126(2):464-8. https://doi.org/10.1213/ANE.00000 00000002387.

7. Yu B, Ouyang B, Ge S, Luo Y, Li J, Ni D, et al. Incidence of postoperative residual neuromuscular blockade after general anesthesia: a prospective, multicenter, anesthetist-blind, observational study. Curr Med Res Opin. 2016;32(1):1-9. https://doi.org/10.1185/03007995.2015.1103213.

8. Bruells CS, Marx G. Diaphragm dysfunction : facts for clinicians. Med Klin Intensivmed Notfmed. 2018;113(7):526-32. https://doi.org/10. 1007/s00063-016-0226-0

9. Dionisio MT, Rebelo A, Pinto C, Carvalho L, Neves JF. Ultrasound assessment of ventilator-induced diaphragmatic dysfunction in Paediatrics. Acta Medica Port. 2019:32(7-8):520-8. https://doi.org/10.20344/amp.10830.

10. Connolly AM, Mittendorfer B. Tracking diaphragm movement by using ultrasound to assess its strength. J Physiol. 2016;594(24):7147-8. https://doi.org/10.1113/jp273313.

11. Umbrello M, Formenti P. Ultrasonographic assessment of diaphragm function in critically ill subjects. Respir Care. 2016;61(4):542-55. https:// doi.org/10.4187/respcare.04412.

12. Goligher EC, Laghi F, Detsky ME, Farias P, Murray A, Brace D, et al. Measuring diaphragm thickness with ultrasound in mechanically ventilated patients: feasibility, reproducibility and validity. Intensive Care Med. 2015;41(4):642-9. https://doi.org/10.1007/ s00134-015-3687-3.

13. Cardenas LZ, Santana PV, Caruso P, Ribeiro de Carvalho CR, Pereira de Albuquerque AL. Diaphragmatic ultrasound correlates with inspiratory muscle strength and pulmonary function in healthy subjects. Ultrasound Med Biol. 2018:44(4):786-93. https://doi.org/10.1016/j.ultrasmedbio.2017.11.020.

14. Carrillo-Esper R, Perez-Calatayud AA, Arch-Tirado E, Diaz-Carrillo MA, Garrido-Aguirre E, Tapia-Velazco R, et al. Standardization of Sonographic diaphragm thickness evaluations in healthy volunteers. Respir Care. 2016;61(7):920-4. https://doi.org/10.4187/respcare.03999.

15. Holtzhausen S, Unger M, Lupton-Smith A, Hanekom S. An investigation into the use of ultrasound as a surrogate measure of diaphragm function. Heart Lung. 2018;47(4):418-24. https://doi.org/10.1016/j.hrtlng.2018.04.010.

16. Minami T, Manzoor K, McCool FD. Assessing diaphragm function in Chest Wall and neuromuscular diseases. Clin Chest Med. 2018;39(2):335-44. https://doi.org/10.1016/j.ccm.2018.01.013.
17. Ueki J, De Bruin PF, Pride NB. In vivo assessment of diaphragm contraction by ultrasound in normal subjects. Thorax. 1995;50(11):1157-61. https://doi.org/10.1136/thx.50.11.1157.

18. Llamas-Alvarez AM, Tenza-Lozano EM, Latour-Perez J. Diaphragm and lung ultrasound to predict weaning outcome: systematic review and Meta-analysis. Chest. 2017;152(6):1140-50. https://doi.org/10.1016/j. chest.2017.08.028.

19. Cohen JF, Korevaar DA, Altman DG, Bruns DE, Gatsonis CA, Hooft L, et al. STARD 2015 guidelines for reporting diagnostic accuracy studies: explanation and elaboration. BMJ Open. 2016;6(11):e012799. https:// doi.org/10.1136/bmjopen-2016-012799.

20. White PF, Song D. New criteria for fast-tracking after outpatient anesthesia: a comparison with the modified Aldrete's scoring system. Anesth Analg. 1999;88(5):1069-72. https://doi.org/10.1097/00000539-19990 5000-00018.

21. Fuchs-Buder T, Claudius C, Skovgaard LT, Eriksson LI, Mirakhur RK, VibyMogensen J, et al. Good clinical research practice in pharmacodynamic studies of neuromuscular blocking agents II: the Stockholm revision. Acta Anaesthesiol Scand. 2007;51(7):789-808. https://doi.org/10.1111/j. 1399-6576.2007.01352.x

22. Cappellini I, Picciafuochi F, Bartolucci M, Matteini S, Virgili G, Adembri C. Evaluation of diaphragm thickening by diaphragm ultrasonography: a reproducibility and a repeatability study. J Ultrasound. 2020. https:// doi.org/10.1007/s40477-020-00462-x.

23. Grams ST, von Saltiél R, Mayer AF, Schivinski Cl, de S Nobre LF, Nóbrega IS, et al. Assessment of the reproducibility of the indirect ultrasound method of measuring diaphragm mobility. Clin Physiol Funct Imaging. 2014;34(1):18-25. https://doi.org/10.1111/cpf.12058.

24. Boussuges A, Gole Y, Blanc P. Diaphragmatic motion studied by m-mode ultrasonography: methods, reproducibility, and normal values. Chest. 2009:135(2):391-400. https://doi.org/10.1378/chest.08-1541.

25. Smargiassi A, Inchingolo R, Tagliaboschi L, Di Marco BA, Valente S, Corbo GM. Ultrasonographic assessment of the diaphragm in chronic obstructive pulmonary disease patients: relationships with pulmonary function and the influence of body composition - a pilot study. Respiration. 2014;87(5):364-71. https://doi.org/10.1159/000358564.

26. Barbariol F, Deana C, Guadagnin GM, Cammarota G, Vetrugno L, Bassi F. Ultrasound diaphragmatic excursion during non-invasive ventilation in ICU: a prospective observational study. Acta Biomed. 2021;92(3):e2021269. https://doi.org/10.23750/abm.v92i3.11609.

27. Cammarota G, Sguazzotti I, Zanoni M, Messina A, Colombo D, Vignazia $\mathrm{GL}$, et al. Diaphragmatic Ultrasound Assessment in Subjects With Acute Hypercapnic Respiratory Failure Admitted to the Emergency Department Respir Care. 2019;64(12):1469-77. https://doi.org/10.4187/respcare.06803.

28. Cappellini I, Picciafuochi F, Ostento D, Danti G, De Gaudio AR, Adembri C. Recovery of muscle function after deep neuromuscular block by means of diaphragm ultrasonography and adductor of pollicis acceleromyography with comparison of neostigmine vs. sugammadex as reversal drugs: study protocol for a randomized controlled trial. Trials. 2018;19(1):135. https://doi.org/10.1186/s13063-018-2525-7.

29. Hemmerling TM, Donati F. Neuromuscular blockade at the larynx, the diaphragm and the corrugator supercilii muscle: a review. Can Anaesth 2003:50(8):779-94 https://doi.org/10.1007/bf03019373.

30. Rocco M, Maggi L, Ranieri G, Ferrari G, Gregoretti C, Conti G, et al. Propofol sedation reduces diaphragm activity in spontaneously breathing patients: ultrasound assessment. Minerva Anestesiol. 2017;83(3):266-73. https://doi.org/10.23736/s0375-9393.17.11615-9.

31. Garofalo E, Bruni A, Pelaia C, Landoni G, Zangrillo A, Antonelli M, et al. Comparisons of two diaphragm ultrasound-teaching programs: a multicenter randomized controlled educational study. Ultrasound J. 2019;11(1):21. https://doi.org/10.1186/s13089-019-0137-4.

32. Calvo-Lobo C, Almazán-Polo J, Becerro-de-Bengoa-Vallejo R, LosaIglesias ME, Palomo-López P, Rodríguez-Sanz D, et al. Ultrasonography comparison of diaphragm thickness and excursion between athletes with and without lumbopelvic pain. Phys Ther Sport. 2019;37:128-37. https://doi.org/10.1016/j.ptsp.2019.03.015.

33. Dülger $E$, Bilgin S, Bulut E, Inal İnce $D$, Köse N, Türkmen C, et al. The effect of stabilization exercises on diaphragm muscle thickness and movement in women with low back pain. J Back Musculoskelet Rehabil. 2018:31(2):323-9. https://doi.org/10.3233/bmr-169749. 
34. Unterbuchner C, Blobner M. Deep neuromuscular blockade : benefits and risks. Anaesthesist. 2018;67(3):165-76. https://doi.org/10.1007/ s00101-018-0425-6.

\section{Publisher's Note}

Springer Nature remains neutral with regard to jurisdictional claims in published maps and institutional affiliations.

- fast, convenient online submission

- thorough peer review by experienced researchers in your field

- rapid publication on acceptance

- support for research data, including large and complex data types

- gold Open Access which fosters wider collaboration and increased citations

- maximum visibility for your research: over $100 \mathrm{M}$ website views per year

At $\mathrm{BMC}$, research is always in progress.

Learn more biomedcentral.com/submissions 